Artigos Originais

\title{
Produções de natureza em territórios em disputa: "Caño Bocón”, Departamento do Guainía, Colômbia
}

\author{
Producciones de naturaleza en territorios en disputa: “Caño Bocón”, Departamento del Guainía, Colombia \\ Nature productions in disputed territories: “Caño Bocón”, Guainía State, Colombia
}

César Augusto Otálvaro-Sierra

Universidade Federal de Uberlândia (UFU), Brasil

DOI: https://doi.org/10.18472/cvt.21n1.2021.1893

Redalyc: http://www.redalyc.org/articulo.oa?

caotalvaros@gmail.com

$\mathrm{id}=115466307001$

Rooselvelt José Santos

Universidade Federal de Uberlândia (UFU), Brasil

rosselvelt@ufu.br

Recepción: 17 Diciembre 2020

Aprobación: 23 Marzo 2021

\section{Resumo:}

A Colômbia vem apresentando múltiplas e profundas transformações sócio-territoriais, as quais contam entre seus detonantes dois processos: o avanço da globalização do sistema capitalista, e os Acordos de Paz de Havana. Estes tem acelerado a abertura de territórios que, tradicionalmente e por conta do conflito armado interno do país e seu isolamento geográfico, tinham experimentado dificuldades na circulação do capital. Perante esse panorama emergem alternativas de desenvolvimento que procuram tornar-se sustentáveis ou menos nocivas à natureza e às populações originárias. Esse artigo é uma análise introdutória ao turismo interessado pelos valores ambientais e paisagísticos do território, a partir da experiência de uma comunidade indígena do Departamento do Guainía (Amazônia colombiana). Poderíamos defini-lo como sendo uma iniciativa que valoriza tais aspectos, bem como estabelecendo ações compromissadas com o desenvolvimento local, como uma estratégia que procura a conservação ambiental, assim como melhorar as condições socioeconômicas das populações que habitam territórios de interesse daquela indústria, mas que apresenta suas próprias contradições e conflitos.

Palavras-Chave: território, natureza, turismo.

\section{ABSTRACT:}

Colombia has been presenting multiple and profound socio-territorial transformations, which count among its detonating two processes: the advance of the globalization of the capitalist system, and the Havana Peace Accords. These have accelerated the opening of territories that, traditionally and because of the country's internal armed conflict and its geographical isolation, had experienced difficulties in the circulation of capital. In view of this scenario, development alternatives emerge that seek to become sustainable or less harmful to nature and native populations. This article is an introductory analysis of tourism interested in the environmental and landscape values of the territory, based on the experience of an indigenous community in the State of Guainía (Colombian Amazon). We could define it as an initiative that values such aspects, as well as establishing actions committed to local development, as a strategy that seeks environmental conservation, as well as improving the socioeconomic conditions of the populations that inhabit territories of interest to that industry, but that presents its own contradictions and conflicts.

KEYWORDS: territory, nature, culture, tourism.

\section{Resumen:}

Colombia viene presentando múltiples y profundas transformaciones socio-territoriales, que cuentan entre sus detonantes dos procesos: el avance de la globalización del sistema capitalista y los Acuerdos de Paz de La Habana. Estos han acelerado la apertura de territorios que, tradicionalmente y por el conflicto armado interno del país y su aislamiento geográfico, habían experimentado dificultades en la circulación de capitales. Ante este escenario surgen alternativas de desarrollo que buscan volverse sustentables o menos dañinas para la naturaleza y las poblaciones nativas. Este artículo es un análisis introductorio del turismo interesado en los valores ambientales y paisajísticos del territorio, a partir de la experiencia de una comunidad indígena del Departamento del Guainía (Amazonia colombiana). Podríamos definirla como una iniciativa que valora tales aspectos, además de establecer acciones comprometidas con el desarrollo local, como una estrategia que busca la conservación ambiental, así como mejorar las 
condiciones socioeconómicas de las poblaciones que habitan territorios de interés para esa industria, pero que presenta sus propias contradicciones y conflictos.

Palabras CLAVE: territorio, naturaleza, cultura, turismo.

\section{INTRODUÇÃo}

Este trabalho visa ser uma análise inicial sobre as transformações na produção de natureza e do território de comunidades indígenas, a partir do desenvolvimento do turismo como alternativa no processo de geração de trabalho, renda e de um modo de vida tradicional na Amazônia colombiana. Faz parte da investigação doutoral do autor, a qual se encontra em andamento sob a orientação do coautor do artigo. Nossas reflexões estão baseadas em dois trabalhos de campo preliminares, de tipo etnográfico, realizados nos meses de janeiro de 2018 e 2019, na comunidade indígena de Barranco Tigre, no Departamento do Guainía da Colômbia. Além disso, desenvolvemos uma revisão de literatura relacionada ao tema, objetivando o conhecimento dos processos envolvidos, a qual será acionada para analisar as transformações na comunidade, abrangendo a produção de natureza e território.

\subsection{Contexto social e geográfico}

A investigação ocorre na comunidade indígena de Barranco Tigre, a qual se localiza às margens do rio Caño Bocón, um tributário do rio Inírida, o qual faz parte da Estrella Fluvial del Inírida, um encontro de águas que configuram os principais afluentes do rio Orinoco. Reconhecida pela sua diversidade biológica, aquele território encontra-se sob a condição internacional de conservação de sítio RAMSAR desde 2014. Esse local faz parte da área geográfica que configura os limites entre as bacias dos rios Orinoco e Amazonas (Noroeste da Amazônia), e se encontra na região da Amazônia colombiana.

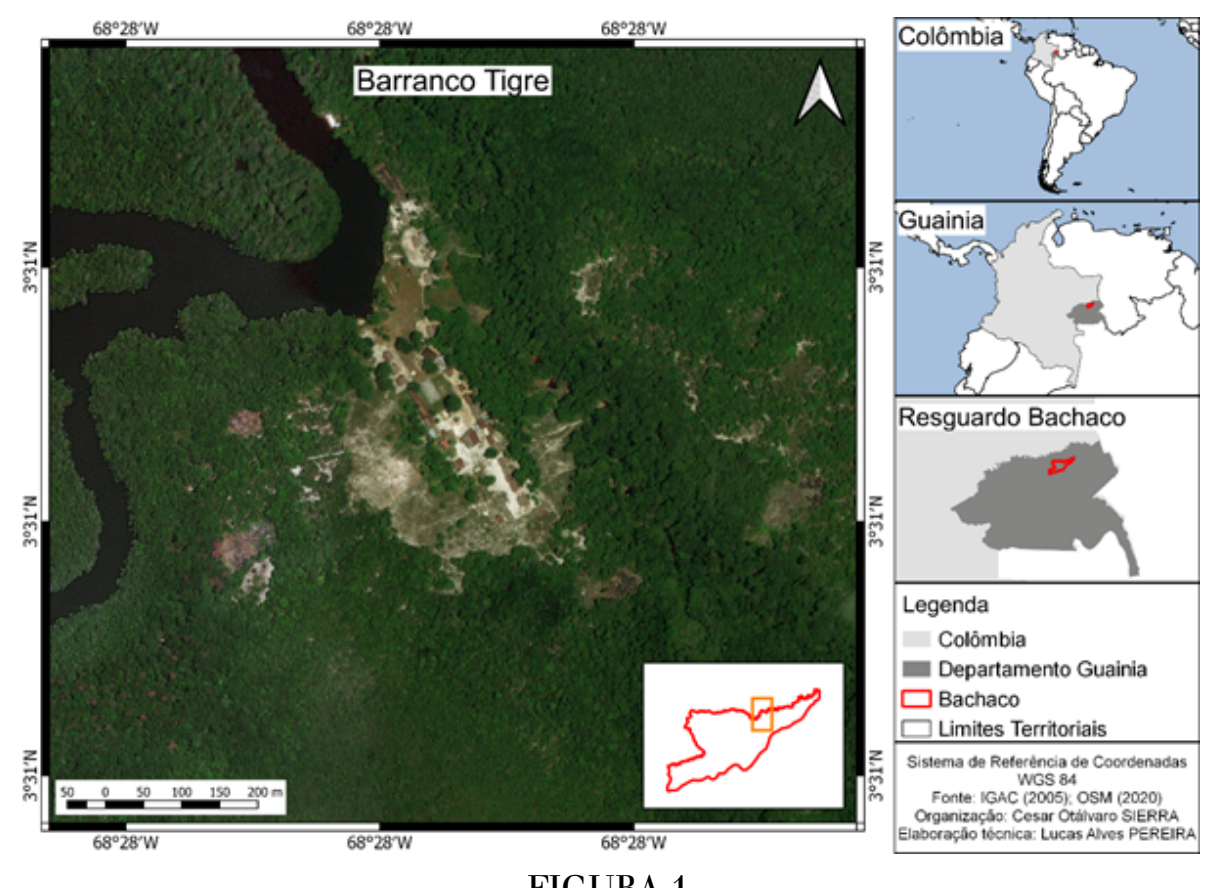

FIGURA 1

Localização da comunidade Barranco Tigre

O território da comunidade indígena de Barranco Tigre faz parte do Departamento do Guainía, mesmo que, quase na sua totalidade, seja composto por Resguardos Indígenas, territórios coletivos com autonomia 
administrativa segundo as leis nacionais (Constitución Política de Colombia, artículos 63, 246, 357; Ley 21 de 1991; Ley 715 de 2001; Decreto presidencial 1953 de 2014), cujo objetivo é a preservação ambiental, social e cultural. Ao mesmo tempo, o Departamento está, quase na sua totalidade, dentro da reconhecida Zona de Reserva Forestal (Ley 2 de 1959). Essa área configura-se em um grande território da nação colombiana (a quase totalidade da sua Amazônia) destinado ao manejo espacial e preservação de ecossistemas estratégicos do país.

Considerando a sua localização, Guainía é um Departamento que se configura como espaço de encontro e intercambio biológico, ecológico, social e cultural, que o coloca como território de alta diversidade e complexidade. No contexto de reprodução ampliada do capital, vem tornando-se atrativo para investimentos econômicos, os quais têm vinculações fundamentalmente com o extrativismo, entendido como um processo de exploração da natureza, assentado na lógica capitalista.

Nos últimos 35 anos a economia daquele território tem se fixado na exploração de recursos da floresta, como a madeira, a mineração de ouro em seus rios, a extração de peixes ornamentais, a pesca comercial, a agricultura e pecuária baseada nos modos de vida dos povos tradicionais e camponeses e, em tempos mais recentes, o turismo.

$\mathrm{Na}$ atualidade, atividades como a pesca comercial e de peixes ornamentais, historicamente importantes para as comunidades indígenas, estão enfrentando as consequências da ampliação da exploração, situação decorrente da intensificação de uma lógica predatória (Franco \& Zuluaga, 2014).

Com relação a mineração, outra das atividades econômicas mais relevantes, permanece em uma incerteza jurídica. Ela é uma atividade incompatível com aquilo que o território representa em termos de conservação. Contudo, embora seja somente praticada pelas comunidades indígenas nos seus territórios, sobre os que têm direitos de manejo especial, devemos levar em consideração o fato de que a totalidade do Departamento do Guainía ficou dentro do que se conhece como Áreas Estratégicas Mineras. Tais áreas foram declaradas pelo Estado central colombiano segundo a existência de reservas estratégicas de minerais, com a intenção de adjudicá-las a grandes companhias mineradoras.

Certamente, esse fato exclui as comunidades tradicionais de se beneficiarem dos resultados daquela atividade (Lopez-Vega, 2016). Neste contexto, resulta que a maioria desta exploração é hoje (2020) realizada de maneira ilegal, com baixa tecnologia e carente de controle de seus impelidos socioambientais, e com o consequente impacto no agravamento das condições de vida das comunidades locais, especialmente as indígenas.

Tal situação pode ser visualizada a partir da cartografia, sobretudo, no que se refere a justaposição de territorialidades. 


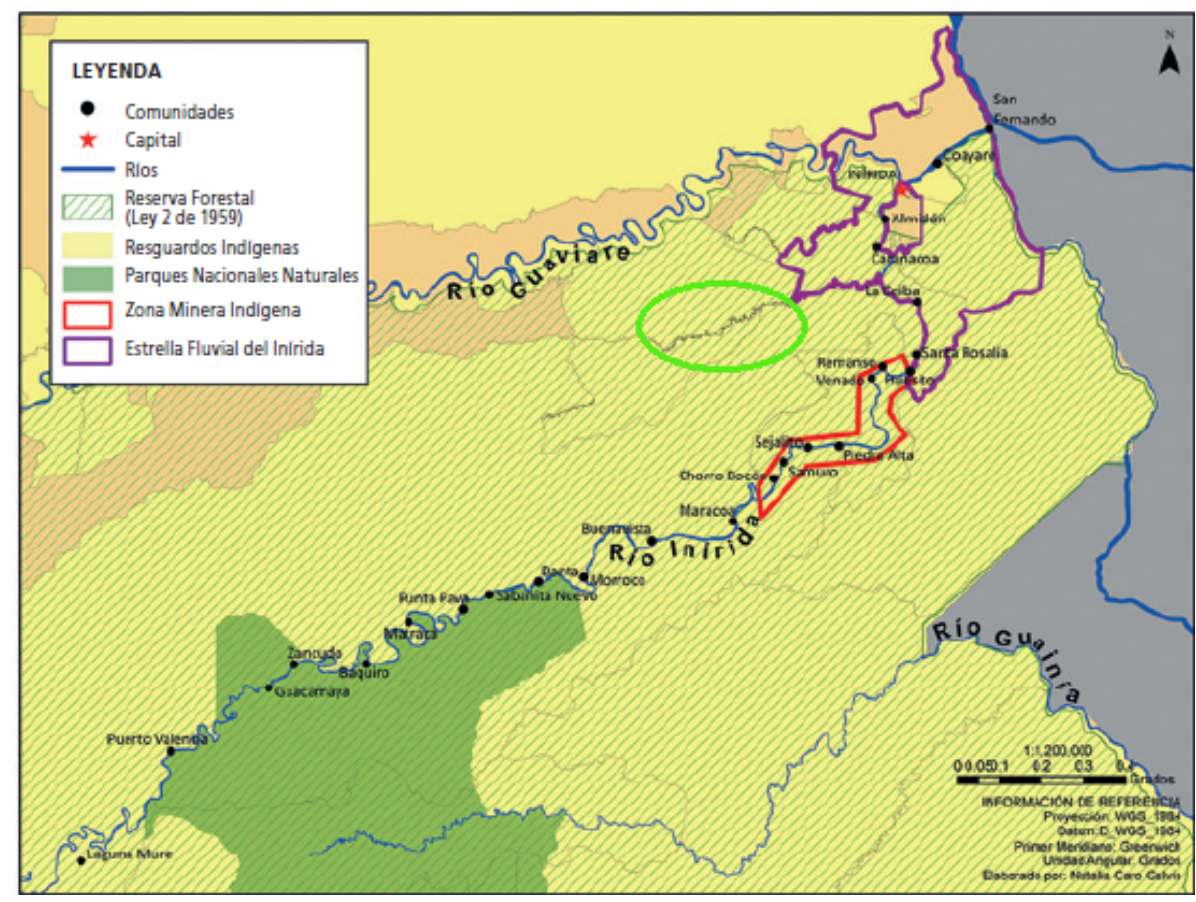

FIGURA 2

Justaposição de territorialidades

Lopez-Vega, 2016, p. 271 (Em verde claro uma aproximação à área de estudo. Modificação feita pelos autores deste artigo).

Aliás as FARC (Fuerzas Armadas de Colombia), a maior guerrilha do País até sua desmobilização em 2016, estiveram interessadas no controle das rendas da mineração de ouro e wolframitas (tungstênio) na bacia alta e média do rio Inírida, o que complicou ainda mais a atividade mineradora tradicional. Porém, é necessário mencionar que foram as comunidades indígenas, a partir da interação direta com as FARC, que impediram sua chegada até a baixa bacia do rio, onde fica a comunidade de interesse desta pesquisa e a capital do Departamento, Puerto Inírida (Lopez-Vega, 2016).

O debate sobre as territorialidades e o uso da noção de multiterritorialidade para pensarmos as dinâmicas sociais, econômicas, políticas, dentre outras que comparecem nos múltiplos territórios na área de estudo, nos fez pensar em termos de justaposição da diversidade territorial bancada pelas co-presenças das comunidades indígenas e as forças revolucionárias colombianas. Naquilo que se refere as dinâmicas territoriais, segundo Haesbaert (2006):

Essas dinâmicas se desdobram num continuum que vai do caráter mais concreto ao mais simbólico, sem que um esteja dicotomicamente separado do outro. No caso de um indivíduo ou grupo social mais coeso, podemos dizer que eles constroem seus (multi) territórios integrando, de alguma forma, num mesmo conjunto, sua experiência cultural, econômica e política em relação ao espaço (Haesbaert, 2006, p. 341).

Além das atividades econômicas já mencionadas, o Guainía também se tem visto imerso nas dinâmicas das economias ilegais (tráfico de drogas, armas e gasolina) e o conflito político armado da Colômbia. Mesmo que nos seus territórios, e especialmente nas áreas mais próximas a sua capital, não se tenham apresentado grandes confrontações militares, sua localização estratégica (extremo sudeste da Colômbia, fronteira com a Venezuela e o Brasil) e a confluência dos seus rios, lhe posicionaram como um território estratégico para a mobilidade de produtos, dinheiro e pessoas vinculadas com ditas atividades. 


\section{Discussão}

\subsection{Abertura dos territórios ao turismo}

Em anos recentes, e especialmente depois de firmado os acordos de paz entre o Governo da Colômbia e a guerrilha das FARC em 2016, alguns departamentos da Amazônia colombiana tem experimentado uma espécie de abertura. Trata-se de interações com o mercado, pois historicamente tinham enfrentado o isolamento físico (é uma região cuja mobilidade e acesso se faz fundamentalmente pelos rios e de avião), junto com o isolamento que impunha a dinâmica do conflito armado.

Esta nova situação permitiu a implantação e fortalecimento de outras dinâmicas econômicas. É o caso do turismo, que viu na diversidade biológica, paisagística e cultural do Departamento do Guanía, diversas possibilidades de reprodução. Assim, além da sua condição de preservação ecológica, aparece a oportunidade de articular seus territórios as dinâmicas da indústria turística, impulsionada pelas leis e planos institucionais do Estado colombiano (Ley 300 de 1996. Plan Sectorial de Turismo 2018-2022), que valorizam essa atividade como fonte de riqueza e de possível desenvolvimento sustentável, especialmente em zonas do país com atrativos naturais e culturais e baixo desenvolvimento econômico.

Neste complexo contexto geográfico, o que claramente configura um espaço de encontro e de múltiplas lutas pelo controle territorial e de seus recursos, se encontra a comunidade indígena de Barranco Tigre. Ela é um povoado Puinave[2] de aproximadamente 28 famílias (Franco \& Zuluaga, 2014, p. 33). Ocupa as margens do rio Caño Bocón e tem se dedicado a agricultura tradicional e a pesca artesanal como atividades econômicas principais no seu território, no qual foram estabelecendo suas territorialidades e um modo de vida relacionado ao conhecimento da natureza. Contudo, nos últimos anos (desde 2015) tem avançado o processo de constituição de uma oferta turística específica, focada na pesca esportiva sob a figura do turismo comunitário, entendido como aquele em que a própria comunidade organizada, administra a oferta dos serviços e os recursos relacionados, usufruindo diretamente dos ganhos econômicos procedentes do trabalho (Layrargues, 2004).

Segundo o Estado colombiano, o turismo comunitário é:

El turismo comunitario debe comprenderse como una estrategia local de aprovechamiento de ventajas comparativas en condiciones complejas desde lo social, económico, ambiental y cultural, que con unas mínimas oportunidades y capacidades pueden transformar su realidad o entorno en oportunidades competitivas para las comunidades involucradas, otorgando así soluciones prácticas a problemas complejos como la paz y el desarrollo. También se constituye en una alternativa innovadora de aprovechamiento de los recursos locales de manera sostenible, que permiten generar empleo y nuevas formas de generación de ingresos económicos a comunidades con recursos económicos limitados o excluidas." (Ministerio de Industria y Turismo, 2012, p.8).

Salientando o papel da sociedade local, tal como pode ser observado no documento do ministério do turismo colombiano:

la oferta de servicios turísticos, por parte de una comunidad organizada, que participa, se beneficia e involucra en los diferentes eslabones de la cadena productiva del turismo, en busca de mayor bienestar, desarrollo y crecimiento económico, valorando las características naturales y culturales de su entorno, que les permite prestar servicios competitivos, sostenibles y de calidad (Ministerio de Industria y Turismo, 2012, p.16).

O turismo comunitário como atividade geradora de renda e trabalho tem como caraterística não ser massivo. Ele encontra-se focado em atividades e clientelas específicas, ao mesmo tempo em que procura se apresentar como exclusivo, oferecendo um território preservado, com uma pesca esportiva de qualidade mundial, com poucos pescadores esportivos visitando-o ao longo do ano. 


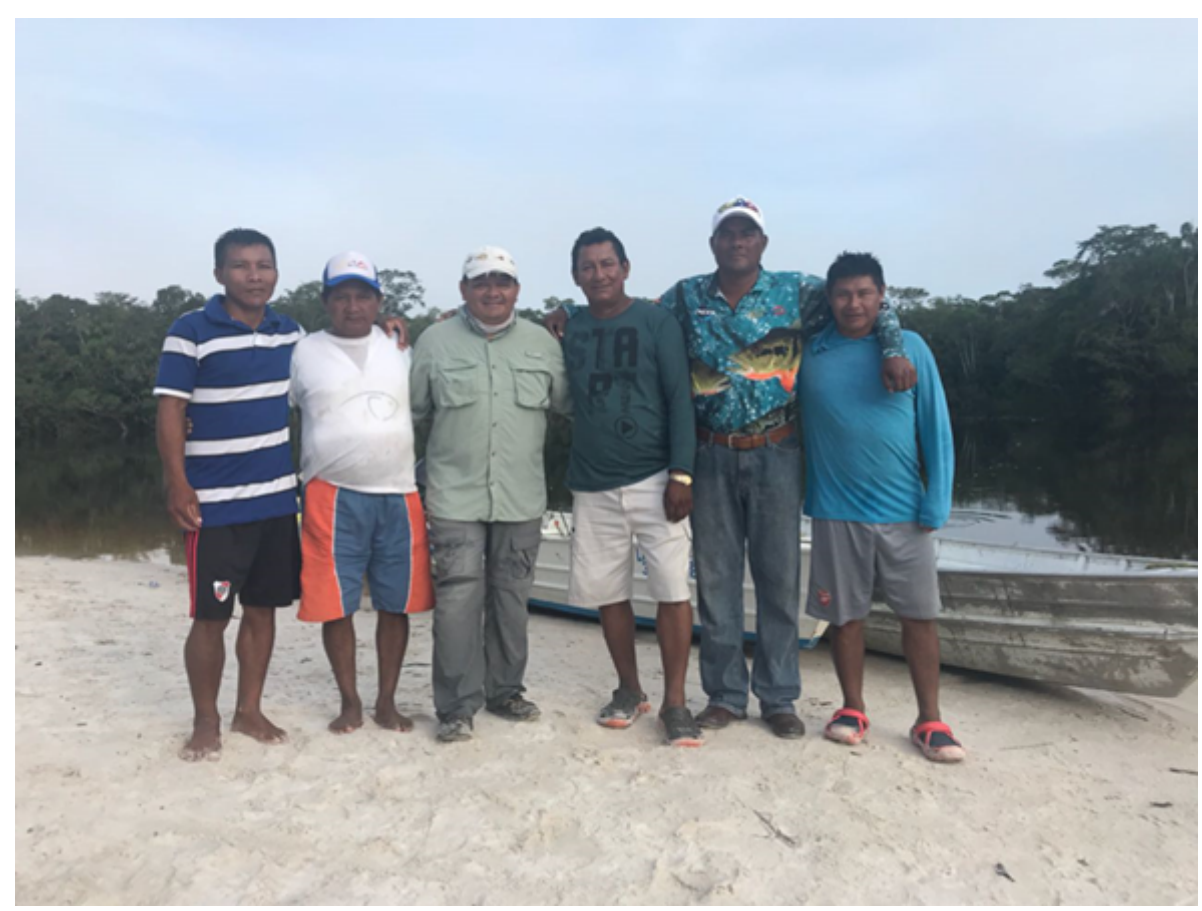

FIGURA 3

Guias de pesca da comunidade Barranco Tigre e pescadores esportivos. acervo pessoal

Embora não compareça nas narrativas das pessoas da comunidade, estabeleceu-se como capacidade de carga ao redor de 200 pescadores esportivos, muito deles estrangeiros. Esse cálculo não é resultado de um estudo técnico de capacidade de carga, mas da própria experiência da comunidade na recepção de turistas, comparecendo na vida prática daquelas pessoas, como uma medida de controle e autoproteção. Para esse contingente a comunidade garante os serviços relacionados a pesca esportiva, exercendo controle de aceso aos lugares de pesca. É uma atividade que acontece entre os meses de dezembro e início de abril, na época de águas baixas, período do ano onde os rios da região apresentam caudal menor por conta da falta de chuvas. Os membros da comunidade, preparados, oferecem seus serviços de guias de pesca e de estadia para os pescadores no seu território. Em geral, criam acampamentos especialmente adaptados para recepcionar o turista.

A partir dos ciclos da natureza, observa-se que o turismo praticado na comunidade se caracteriza como uma atividade estacional. No lugar, a sua implementação tem trazido mudanças evidentes como o aumento do fluxo de renda em dinheiro na comunidade, repercutindo nos ganhos monetários das famílias. Também tem gerado na comunidade ações no sentido de promover um maior controle de aceso ao território.

Contudo, trata-se de ações que transformam as relações no e com o território. Ao se afirmar que o turismo transforma o espaço social de proteção, produção e reprodução social (material e simbólico), também se compreende que ele é uma fonte alternativa de geração de novos ingressos de pessoas, recursos financeiros e valores humanos.

O turismo praticado no lugar, ao derivar de uma atividade que é julgada como sustentável, se apresenta como uma alternativa de resistência e também de refutação a outras práticas sócio-produtivas, como a mineração, a qual é vista, pela comunidade, como um perigo para o território. $\mathrm{Na}$ comunidade, a mineração encontra-se associada a diversos conflitos sociais e deterioração socioambiental.

Porém, outras tensões vão comparecendo neste processo de mudanças. $\mathrm{O}$ turismo também tem apresentado agitações com outras comunidades, como aquelas que se encontram em águas baixo do rio Caño Bocón. O principal desentendimento decorre do aumento dos visitantes e embarcações que transitam pelos seus territórios. Esses conflitos estão sendo conduzidos pelos líderes das comunidades, conhecidos como 
Capitanes (Capitães). O objetivo é incluir essas outras comunidades na atividade turística descrita, com o fim de expandir a atividade turística e evitar as confrontações.

\subsection{Turismo e processos de permanência territorial comunitária}

No caso do Departamento do Guainía, assim como grande parte da Amazônia colombiana, pode se evidenciar como sua articulação às dinâmicas regionais, nacionais e internacionais do capitalismo tem se levado fundamentalmente pelas dinâmicas extrativas, estratégia central na articulação da periferia capitalista, desde a exploração de látex no início do século $\mathrm{XX}$, até as dinâmicas contemporâneas da grande mineração e o aproveitamento transacional dos recursos biológicos.

Essa trajetória histórica e espacial carrega consigo, um de seus fundamentos, a transformação da noção de natureza e suas características. Como processo, vai desde sua concepção, como sendo aquilo que comparece fora do âmbito humano, que deve e pode ser dominado e aproveitado em benefício da sociedade (noção de recurso), até sua concepção como patrimônio da humanidade que deve ser resguardado e sua funcionalidade conservada, e por tanto ser explorado de um jeito racional e sustentável (noção de patrimônio sustentável) Desse modo, em meio a processos contraditórios, as compreensões de natureza, nas diversidades de objetivos, por um lado, continuam servindo de estratégias para garantir a continuidade do capitalismo, como assinala Arturo Escobar (Escobar. 2010), e pelo lado das comunidades tradicionais, como meio delas tentarem assegurar as suas possibilidades de reprodução social, como almejado pela comunidade de Barranco Tigre.

Nesse propósito de pensar a sustentabilidade é esclarecedor as análises de Ulloa e Coronado, quando afirmam e reiteram a necessidade de considerar os processos de construção de territórios e territorialidades:

Hay diversidad de procesos de construcción de territorios y territorialidades articulados a variadas nociones de naturaleza. Los extractivismos requieren la construcción de territorio y el ejercicio de territorialidad acordes con una visión específica de naturaleza y determinados intereses económicos y políticos, articulados a diversas escalas globales, con implicaciones locales. Ante estas, por ejemplo, los pueblos indígenas demandan el reconocimiento de sus territorios como espacios de vida y como seres vivos (Ulloa \& Coronado, 2016, P. 43)

Assim, considerando a diversidade dos processos territoriais, poderia se afirmar que o que acontece em grande parte da Amazônia colombiana, bem como no território de interesse específico desta pesquisa, é a mudança nas concepções e usos de natureza e o seu encontro no território. Deste modo, as finalidades dos projetos de desenvolvimento devem atingir uma hegemonia cognitiva e política, que permita o seu aproveitamento segundo interesses específicos e concepções políticas particulares.

No caso do território da comunidade de Barranco Tigre, é evidente como o turismo aparece como alternativa de continuidade do grupo social no território assim como de sua autonomia, perante o avanço dos interesses e as práticas desterritorializantes e reterritorializantes da mineração transacional, assim como possibilidade de rompimento do histórico isolamento social e econômico que tem experimentado.

O território passa a ser recriado e projetado ao mundo como um conjunto de estratégia de produção e reprodução social e cultural, por meio de seu aproveitamento a partir de reivindicações políticas. Nesse caminho vai se tornando objeto de troca, incluindo sua preservação. Seus atributos ambientais passam a representar opções de destino turístico a serem usados como um valor economicamente mensurável, no sentido de que outros, que vem de fora, pagam para desfrutá-los.

A partir do turismo receptivo é preciso criar estratégias de administração que permitam usufruir da natureza para gerar renda, sem pôr em risco sua continuidade como atrativo e de vida social em comunidade. Assim, uma das possibilidades de desenvolvimento está ligado ao turismo comunitário que explora a pesca esportiva. A comunidade Barranco Tigre, organizada politicamente, poderá ainda potencializar o aproveitamento cultural da sua comunidade, incluindo saberes e fazeres desenvolvidos em seu território, por exemplo a culinária, o artesanato, plantas e ervas medicinais. 
Trata-se de uma transformação do território por via da recriação de relações com a natureza, possibilitando novos usos que incluam as demandas locais e do turismo. A natureza pensada para além de valores econômicos inclui novas práticas sociais, racionalidades, posições políticas e produção da natureza. Nesta perspectiva, a natureza poderá comparecer na atividade turística como fornecedora dos meios materiais e simbólicos para a existência humana. Os seus usos ultrapassam o sentido de fornecer os recursos que sustentam a produção em si mesmo. A apropriação da natureza, segundo lógicas indígenas locais, poderá converter as práticas sociais tradicionais em um conjunto de estratégias em que a conservação se torne característica fundamental da atividade turística. Um conjunto de atividades especificas e coerentes com a vida que existe nos lugares, capaz de usar aquilo que se tornou escasso na atualidade, fazendo com que a proposta comunitária de aproveitamento da natureza pense o turismo para além do mercado.

É um movimento que indica oposição ao que Harvey (2007) assinala como a expansão do capitalismo no mundo, atingindo o controle de territórios que estavam fora (não determinados) por suas dinâmicas políticas e econômicas, o qual se consegue por via da atribuição de valores monetários, valores de troca, a esses territórios. A lógica é esvaziar-lhes de seus conteúdos culturais para serem facilmente mercadejados.

Opondo-se à lógica de mercado de transformar tudo em mercadoria, o turismo praticado na comunidade poderá ampliar as suas diferenças na medida em que conseguir se apresentar como uma tentativa de manterse autônomo à conquista do capital sobre o seu território cultural. Nesse momento o turismo comunitário marca a entrada da valoração da natureza na lógica comunitária de preservar para existir. A estratégia parece ser a de atrair os interesses de diversos turistas, mas administrando o número de visitantes em aproximadamente 200 pessoas por ano, contingente que a comunidade avalia como importante para não pôr em risco a sua autonomia. Temeridade real e concreta quando se trata de exploraçóes turísticas comandadas por investimentos capitalistas, já assinaladas por Guilland e Ojeda (2012), em suas análises sobre experiências de turismo em três territórios indígenas da Colômbia. Para as autoras, as comunidades não só ficaram fora do controle do negócio, como também têm sofrido pressões de donos de capitais investidos nele, e do próprio Estado.

Na prática, as forças políticas e econômicas hegemônicas têm trazido deslocação de populações originárias, simplificação e mercantilização dos significados do território e da identidade cultural, com o fim de gerar um produto "light" que encaixe facilmente no mercado turístico atual, sensível às questões da sustentabilidade ambiental e a justiça social.

Contra esses encaixes, comparecem as estratégias de vida da comunidade. Como relacionadas à lógica social de viver da floresta, promovendo sustentabilidade, também podem ser interpretadas como uma reação ante as pressões de outros interesses que olham para o território, enxergando-o como espaço vazio. A mineração empresarial, por exemplo, concebe o território indígena como depósito de recursos a serem explorados, indicando outras formas de apropriação territorial. Além da apropriação, a mineração tem sido associada pelos indígenas às temidas repercussões da atividade na deterioração ambiental e social.

O turismo como é conduzido por essa comunidade parte do objetivo de desenvolver possibilidades de permanecia no seu território, reivindicando o seu direito de geri-lo segundo seus conhecimentos e interesses amparados na autonomia que lhes dá a lei e assim protegê-lo, que é o mesmo que proteger-se, perante o avanço desses outros interesses interpretados como perigosos.

Permanecer é, ao mesmo tempo, desenvolver melhorias na qualidade de vida por conta dos novos recursos econômicos ingressantes a partir do turismo na comunidade. Estamos compreendendo que a geração de renda propiciada com a prática do turismo é significativa para as comunidades que têm enfrentado diversos isolamentos (físicos e sociais), e limitações associadas às dificuldades de infraestruturas na articulação das dinâmicas socioeconômicas para além do local.

Nesse sentido, e como propóe Escobar (2010), o turismo pode ser interpretado como uma articulação estratégica às dinâmicas do capital e da globalização, num movimento re-interpretativo e organizacional. Em grande parte, permite aos investidores conservarem autonomia, protegendo a continuidade do que Harvey 
denomina como processos “socioecologicos" (Harvey, 2017, p. 265) constituintes do espaço, onde a natureza e a cultura não são âmbitos separados senão inter-relacionados, produzidos em uma ordem superior, o que demanda compreender a mudança nas formas de vida como uma transformação de relações sociais e ecológicas produtoras de natureza.

\section{CONSIDERAÇões FINAIS}

A experiência com o turismo como empreendimento econômico e projeto de vida comunitário[3], da comunidade de Barranco Tigre, no Departamento do Guainía da Colômbia, apresenta a oportunidade de compreender como, nas dinâmicas contemporâneas do capital, os territórios étnicos vêm sendo atingidos por elas. Nesse processo também é possível observar reações, ao mesmo tempo em que se constroem reinterpretações e articulações estratégicas a ditas dinâmicas, na procura da continuidade desses territórios.

Se configura, assim, um confronto de interesses e de concepções sobre esses territórios, no bojo do qual ficam diversas concepções sobre a natureza, as quais podem justificar ou rejeitar esses interesses, suas intervenções e efeitos socioespaciais. Portanto, é necessário ultrapassar os tratamentos tradicionais sobre o conceito de natureza, que a têm concebido como um fenômeno externo e separado do mundo social, para compreendê-la como uma produção humana resultante da ação da sociedade por meio do trabalho (Smith, 2008), com o qual podemos compreender melhor como essa natureza apresenta transformações materiais e de sentido de origem histórico, fundamentais para seu aproveitamento e para enxergar as particularidades de sua relação com a sociedade, assim como as mudanças nessas relações.

Propõe-se, então, uma aproximação à natureza na linha da proposta de Santos para a compreensão do espaço (2017), onde sistemas de fixos e de fluxos se encontram e põem em jogo seus conteúdos técnicos e culturais, de origem histórica, ficando no meio das brigas pelo poder de determinar as ações fundamentais nessa natureza, e do que se pode e não pode fazer nela ou com ela.

No caso exposto nestas páginas, uma nova aproximação econômica ao território vem gerando uma transformação na natureza, nas formas em que ela é compreendida, conservada e produzida. A interação com dinâmicas desterritorializantes e reterritorializantes de outras escalas espaciais, impõe no lugar de vida, reações das pessoas.

No intento de conservar a capacidade de definir uma forma de vida que responda as necessidades e interesses próprios, por meio do turismo e a comercialização dos atributos naturais do território, essa tentativa se localiza nas contradições próprias de justificar a criação de uma natureza na lógica de uma comunidade indígena. Com a intenção de continuar existindo no território objetiva-se o seu aproveitamento de forma que não leve à deterioração da vida e à perda da autonomia comunitária sobre ela. Tudo isso acontece em um contexto histórico onde o despojo e o consumo em função do ganho têm sido as vias históricas da implantação do capitalismo nos territórios.

\section{Agradecimentos}

Agradecimentos à Coordenação de Aperfeiçoamento de Pessoal de Nível Superior - CAPES, Brasil, pelo financiamento dos estudos de doutorado do autor deste artigo, o qual fez possível sua elaboração.

\section{ReFERÊNCIAS}

Cosntitución Política de Colombia de 1991. (1991). Gaceta Constitucional No. 116 de 1991. http://www.secretari asenado.gov.co/senado/basedoc/constitucion_politica_1991.html

Decreto presidencial 1953 de 2014 por el cual se crea un régimen especial con el fin de poner en funcionamiento los Territorios Indígenas respecto de la administración de los sistemas propios de los pueblos indígenas hasta que el 
Congreso expida la ley de que trata el artículo 329 de la Constitución Política. (2014). Disponível em: http://w ww.secretariasenado.gov.co/senado/basedoc/decreto_1953_2014.html.

Escobar, A. (2010). Una minga para el postdesarrollo: lugar, medio ambiente y movimientos sociales en las transformaciones globales. Universidad Nacional Mayor de San Marcos.

Franco, M., \& Zuluaga, P. (2014). Comportamiento de pescadores frente a distintos arreglos institucionales en la Estrella Fluvial de Inirida. Amazonía colombiana. International Resources Group (IRG). https://www.conservation-st rategy.org/publication/comportamiento-de-pescadores-frente-distintos-arreglos-institucionales-en-la-estrella

Guilland, M., \& Ojeda, D. (2012). Indígenas "auténticos" y campesinos "verdes". Los imperativos identitarios del turismo en Colombia. Cabiers des Amériques latines, n. 71, 1-22. https://doi.org/10.4000/cal.2689

Haesbaert, R. (2006). O mito da desterritorialização: Do "fim dos territórios" à multiterritorialidade (2a ed.) Bertrand Brasil.

Harvey, D. (2007). Espacios del capital: hacia una geografía crítica. Akal.

Harvey, D. (2017). El cosmopolitismo y las geografias de la libertad. Akal.

Layrargues, P. (2004) A Função Social do Ecoturismo. Boletim Técnico Do Senac, n. 30(1), 38-45. https://doi.org/1 0.26849 /bts.v30i1.508

Ley 2 de 1959 sobre Economía Forestal de la Nación y Conservación de Recursos Naturales Renovables, (1959). htt p://www.suin-juriscol.gov.co/viewDocument.asp?ruta=Leyes $/ 1556842$

Ley 21 de 1991 por medio de la cual se aprueba el Convenio número 169 sobre pueblos indígenas y tribales en países independientes, adoptado por la 76a. reunión de la Conferencia General de la O.I.T., Ginebra 1989, (1991). ht tp://www.suin-juriscol.gov.co/viewDocument.asp?ruta=Leyes/1577376

Ley 715 de 2001 por la cual se dictan normas orgánicas en materia de recursos y competencias de conformidad con los artículos 151, 288, 356 y357 (Acto Legislativo 01 de 2001) de la Constitución Política y se dictan otras disposiciones para organizar la prestación de losservicios de educación y salud, entre otros. (2001). Disponível em: http://www.secretariasenado.gov.co/senado/basedoc/ley_0715_2001.html

Ley 300 de 1996 por la cual se expide la Ley General de Turismo y se dictan otras disposiciones. Congreso de la República de Colombia, (1996). http://www.secretariasenado.gov.co/senado/basedoc/ley_0300_1996.html

López-Vega, J. (2016). Desafíos de la movilización minera interétnica en el río Inírida, Guainía, al posconflicto en Colombia. In: Ulloa, A., \& Coronado, S. (Orgs.). Extractivismos y posconflicto en Colombia: retos para la paz territorial. (pp. 267-302) Universidad Nacional de Colombia.

Ministerio de Industria y Turismo. República de Colombia. (2012). Lineamientos de política para el desarrollo del turismo comunitario en Colombia. https://www.mincit.gov.co/CMSPages/GetFile.aspx?guid=58fc480a-7a274420-aac4-e72c8bcee437

Santos, M. (2017). A Natureza do Espaço: Técnica e Tempo. Razão e Emoção. (4. ed.) Editora da Universidade de São Paulo.

Smith, N. (2008). Uneven Development: Nature, Capital, and the Production of Space. (3a ed.) The University of Georgia Press.

Ulloa, A., \& Coronado, S. (2016). Territorios, Estado, actores sociales, derechos y conflictos socioambientales en contextos extractivistas: aportes para el posacuerdo. In: Ulloa, A., \& Coronado, S. (Orgs.). Extractivismos y posconflicto en Colombia: retos para la paz territorial. (pp. 23-58) Universidad Nacional de Colombia.

\section{Notas}

[1] Para efeito de esclarecimento, a Colômbia é um Estado unitário organizado em 32 departamentos descentralizados, cada um com uma capital departamental, e um Distrito Capital (Santa Fé de Bogotá) sede do Governo Nacional e capital do país. Os governadores dos departamentos são eleitos de quatro em quatro anos e fazem parte do poder executivo. Comparativamente, no caso Brasileiro, o país é constituído política e administrativamente por 27 unidades federativas. São 26 estados e um distrito federal. O governador eleito de quatro em quatro anos representa o poder executivo. 
César Augusto Otálvaro-Sierra, et al. ProduÇões de natureza em territórios em disputa: “Caño Bocón...

[2] "El pueblo Puinave se ubica al oriente del territorio colombiano, principalmente en el departamento Guainía, en las riberas de los ríos Inírida y Guaviare, y también en los departamentos del Guaviare y el Vichada (Triana, 1987).” http:// www.onic.org.co/pueblos/1137-puinabe

[3] Onde o econômico é uma parte das suas propostas de terem direito ao desenvolvimento sem perderem seus territórios e territorialidades. 